\title{
Photodynamic Combined with Magnetic Field Applications for Viability Activation of Anaerobic Photosynthetic Bacteria
}

\author{
Suryani Dyah Astuti ${ }^{1, a}$, Nike Dwi GD ${ }^{1}$, Agus Supriyanto ${ }^{2}$, Kuwat Triyana ${ }^{3, b}$ \\ ${ }^{1}$ Department of Physics, University of Airlangga, Surabaya Indonesia \\ ${ }^{2}$ Department of Biology, University of Airlangga, Surabaya Indonesia \\ ${ }^{3}$ Department of Physics, Universitas Gadjah Mada, Sekip Utara BLS.21 Yogyakarta Indonesia \\ asuryanidyah@gmail.com; btriyana@ugm.ac.id (corresponding author)
}

Keywords: activation, light emitting diode, magnetic, photodynamic, rhodobacter sphaeroides, viability

\begin{abstract}
This paper reports the influence of light exposure (photodynamic) combined with magnetic field application on viability activation of anaerobic photosynthetic bacteria (Rhodobacter sphaeroides). For this purpose, a customized equipment was developed. It consisted of a sample holder, arrays of light emitting diode (LED) and Helmholtz coils as light source and magnetic field source, respectively. The systems of this equipment were controlled by a microcontroller of AVR ATMega-8535. Prior to application in vitro, all arrays of LED were calibrated, both their intensity and wavelength. After the treatments, all bacteria colonies were grown in photosynthetic media (PMS) for 48 hours followed by calculating the growth of bacterial colonies using a total plate count (TPC) method and Quebec colony counter. As results, it was found that the growth of bacterial colonies was influenced by both light intensity and wavelength of LED array. At the same intensities, the wavelength of $430 \mathrm{~nm}$ showed highest effect on the growth of bacterial colonies. In addition, upon application of the optimum light combined with magnetic field, the highest growth of bacterial colonies was achieved more than $110 \%$ when the energy dose of light and the magnetic field were $204 \mathrm{~J} / \mathrm{cm}^{2}$ and $1.8 \mathrm{mT}$, respectively.
\end{abstract}

\section{Introduction}

Photosynthetic bacteria are widely distributed in environment and wastewater [1]. They contain photosynthetic pigments of bacteriochlorophylls (BChl) and carotenoids which can grow either in a phototrophic and a heterotrophic condition depending on the presence or absence of light [2]. The pigments have their distinctive electronic absorption bands depending on molecular structures. Photosynthetic bacteria possess a modular photosynthetic apparatus in which a photochemical reaction center $(\mathrm{RC})$ is fed with energy by a closely associated light harvesting pigment-protein (LH1) [3]. In many species these so called RC-LH1 complexes are in turn surrounded in the photosynthetic membrane by one or more types of peripheral light harvesting complexes [4].

Photosynthetic bacteria can produce various types of physiological active substance such as vitamin $\mathrm{B}_{12}$, ubiquinone (coenzyme Q10), 5-aminolevulinic acid (ALA), porphyrins and RNA. In particular, ALA of photosynthetic bacterial was commercially applied to medical diagnosis and treatment [5]. Most bacteria use hemA biosynthetic pathway to produce porphyrins from a precursor. The ALA can be synthesized biologically by two distinct metabolic pathways. Differences between the bacterial and mammalian pathways include the existence of a widely used alternative route to ALA from glutamate and offshoots from the pathway that lead to the hemA variants and coenzyme B12 [6]. In the bacterial, ALA is formed by an enzyme ALA synthase that catalyzes the pyridoxal phosphate-dependent condensation of succinyl coenzyme A (succinyl-CoA) and glycine. The ALA synthase is the product of the hemA gene in Rhodobacter sphaeroides [7].

There are many techniques to increase production of ALA such as by adjusting $\mathrm{pH}$, carbon and nitrogen source, precursor concentrates, light illumination, aeration, and magnetic field application [5-7]. Additionally, it has been reported by other researchers that the application of magnetic field on the Rhodobacter sphaeroides colonies causes a stress on bacteria cells and activates ALA dehydratase (ALAD) genes. The ALAD is an important enzyme of phorphyrin synthesis [8]. This study aims to investigate effects of energy dose illumination of monochromatic light combined magnetic field application on the growth of Rhodobacter sphaeroides colonies. 